\title{
Observations of Nonlinear Effects in Directional Spectra of Shoaling Gravity Waves
}

\author{
M. H. Freilich \\ Jet Propulsion Laboratory, California Institute of Technology, Pasadena \\ R. T. GuZA \\ Center for Coastal Studies, Scripps Institution of Oceanography, La Jolla, California
}

\author{
S. L. Elgar
}

Electrical and Computer Engineering, Washington State University, Pullman

\begin{abstract}
The spatial evolution of a directionally spread wave field on a near-planar natural beach is examined using data from longshore arrays of pressure sensors and wave staffs at $10.3 \mathrm{~m}$ and $4.1 \mathrm{~m}$ depth. High-resolution frequency-directional spectra from the deeper array are used to initialize a linear refraction model, and the resulting model predictions are compared with frequency-directional measurements at the shallow array. Linear theory inaccurately predicts both the shapes of directional spectra in shallow water and the total variances in some frequency bands. The discrepancies are largest for frequencies associated with maxima in the bicoherence spectrum, suggesting the importance of nonlinear effects. Furthermore, the measured directional spectrum at energetic low frequencies $(0.05-0.11 \mathrm{~Hz})$ and the vector resonance conditions for triads of long waves can be used to predict accurately the directions of observed peaks in directional spectra at higher frequencies $(0.12-0.21 \mathrm{~Hz})$. Prominent features in the measured directional spectra at the shallow array are thus consistent with energy transfers resulting from near-resonant triad interactions in the shoaling wave field.
\end{abstract}

\section{INTRODUCTION}

Nonbreaking water waves evolve substantially as they propagate shoreward in shallow water. As the depth decreases, wave amplitudes increase and initially symmetric wave profiles and oscillatory currents become asymmetric and skewed. Both linear and nonlinear processes act simultaneously to alter the frequency-directional characteristics of shoaling waves. The present study aims to identify qualitatively the nonlinear contribution to the shoaling transformation of frequency-directional spectra for natural waves propagating on a beach with nearly planar bathymetry.

Variations in water depth cause refraction, resulting in spatial changes in the amplitudes and directions of linear wave fields [e.g., Longuet-Higgins, 1957; Collins, 1972; LeMéhaute and Wang, 1982]. On most beaches, waves become more directionally collimated and amplitudes increase as the depth decreases. The linear refraction theory for wave fields that are broad in both frequency and direction has been developed extensively and applied to a variety of coastal surface wave studies, ranging from qualitative works [e.g., Hom-ma et al., 1966; Wilson et al., 1973; Pawka, 1983] to numerical modeling of the full linear transformation of the frequency-directional spectrum by topography [e.g., Pawka et al., 1984]. Linear theory has been reasonably successful in predicting directional characteristics of refracted waves in relatively shallow water, given estimates of deep water directional spectra and knowledge of the bathymetry.

However, it has long been recognized that linear refrac-

Copyright 1990 by the American Geophysical Union.

Paper number 90JC00354.

0148-0227/90/90JC-00354\$05.00 tion theory is not uniformly valid. Even for initially infinitesimal waves normally incident on plane beaches, the linear theory predicts large wave amplitudes near the shore, thus violating the underlying assumption of linearity. When the initial wave field and/or the bottom topography varies spatially, linear refraction may predict the existence of caustic regions where the waves are neither slowly varying nor of small amplitude. Near such caustics, diffractive and nonlinear analyses are required (see Peregrine and Smith [1979, and references therein] for the cases of fully dispersive and nondispersive waves). While of fundamental importance for understanding interactions between dispersive waves and currents [Peregrine and Smith, 1979; Peregrine and Thomas, 1979], essentially monochromatic nonlinear analyses are not applicable to the shoaling region, where the wave fields are simultaneously weakly nonlinear, weakly dispersive, and broadbanded in frequency and (perhaps) direction.

On Pacific beaches, wind waves and swell in depths less than about $10 \mathrm{~m}$ are both weakly nonlinear and weakly dispersive. Near-resonant triad interactions can thus cause cross-spectral energy transfers and modal phase modifications as the waves propagate shoreward. Freilich and Guza [1984](hereinafter FG) and Liu et al. [1985](hereinafter LYK) have developed nonlinear shoaling models based on variants of the Boussinesq equations for long waves propagating in variable depth [Peregrine, 1972]. The models have no adjustable parameters, and the one-dimensional model of FG (which assumes that all waves are normally incident on a beach with no alongshore depth variations) has been successfully tested against extensive field observations on several beaches and for a variety of wave conditions [FG; Elgar and Guza, 1985a; Elgar et al., 1990]. 
The most straightforward empirical search for nonlinear effects on the evolution of directional wave fields involves comparing measured frequency-directional spectra $(S(f, \theta))$ with the predictions of linear refraction theory. This requires measurements of $S(f, \theta)$ at two depths, since the data obtained in deeper water are used to initialize the linear refraction model. During a field experiment conducted in $1980, S(f, \theta)$ was measured with two linear arrays of wave gages deployed at approximately $10 \mathrm{~m}$ and $4 \mathrm{~m}$ depths. The arrays were separated by $246 \mathrm{~m}$ in the cross shore, and the bottom topography between the arrays was smooth and nearly planar. The large alongshore extent of the arrays and the use of data adaptive processing techniques resulted in high directional resolution and accuracy over the wind wave frequency band.

In the case study reported here, $5 \mathrm{~h}$ of continuous data from the two directional arrays are used to show that nonlinear effects influence the evolution of the frequencydirectional spectrum in the shoaling region, as suggested by the theoretical models of FG and LYK. Measurements at 10 $\mathrm{m}$ depth (and hence the predicted directional spectra at $4 \mathrm{~m}$ depth) were dominated by swell propagating from the south at low frequencies $(<0.09 \mathrm{~Hz})$ and by waves propagating from the north at higher frequencies. However, the measured two-dimensional spectra in shallow water showed evidence of significant southerly energy at harmonics of the incident swell that was not predicted by linear theory. In addition, linear theory did not predict observations of nearly normally incident energy found at the sum frequency of the south swell and the higher-frequency north "sea". These deviations between the measurements and the linear theory occurred at frequencies where the bicoherence was high, indicating significant nonlinear coupling within wave triads. Additionally, by using the bicoherence (to identify the frequencies of waves in a triad), the observed propagation directions for waves at two of the frequencies, and the vector resonance conditions presented by FG and LYK, the observed directions associated with apparently nonlinearly generated waves can be predicted accurately. The results presented for this particular subset of the data are also found to varying degrees in data obtained on many other occasions during this experiment.

The field experiment and data analysis are described in section 2. Measured frequency-directional spectra, and comparisons between predictions of linear refraction theory and data from the shallow array are presented in sections 3 and 4 , respectively. Analyses of the discrepancies between measured shallow water directional spectra and those predicted by linear theory are given in section 5 . Discussion and conclusions follow in section 6 .

\section{Field EXPERIMENT AND DATA ANALYSIS}

Extensive measurements of shoaling waves collected throughout September 1980 at Torrey Pines Beach in southern California are described in detail in FG. Wave frequency-directional measurements for the present study were obtained from longshore arrays of six bottom-mounted pressure sensors ( $\sim 10 \mathrm{~m}$ depth) and six surface-piercing wave staffs ( $\sim 4 \mathrm{~m}$ depth) shown in Figure 1.

The offshore array ( $\sim 10 \mathrm{~m}$ depth) was 395 in total length. A five-sensor version of this array was established by Pawka [1982] and used for a series of investigations into the effects

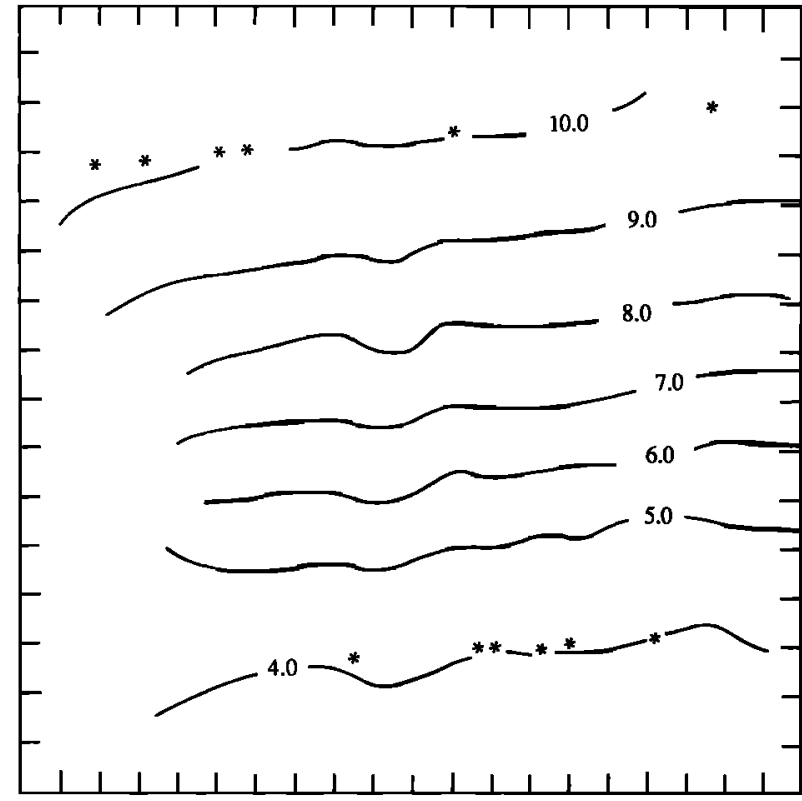

Fig. 1. Bathymetry at the Torrey Pines site, based on 1028 fathometer measurements obtained on September 9, 1980. Contour interval is $1 \mathrm{~m}$. The locations of the sensors in the longshore arrays are denoted by asterisks. Ticks on axes are $25 \mathrm{~m}$ apart.

of island shadowing on the nearshore wave climate [Pawka, 1983; Pawka et al., 1984]. A sixth sensor added for the 1980 experiment increased the aliasing frequency to $0.20 \mathrm{~Hz}$ (cf. FG). Extensive testing by Pawka [1982, 1983] showed that the array could resolve bidirectional wave trains at $f=0.067$ $\mathrm{Hz}$ separated by only $8^{\circ}$ in direction (and varying significantly in relative amplitudes) when using maximum likelihood estimation. Greater angular resolution is achieved by using the iterative maximum likelihood estimation technique [Pawka, 1982, 1983; Oltman-Shay and Guza, 1984] described briefly below.

The shallow array was $192 \mathrm{~m}$ in longshore extent and was designed specifically to provide measurements of twodimensional spectra for comparison with those measured at the deep array. Although the relative placements (longshore lags) of the wave staffs in the shallow array were not identical to those in the deep array, the shallow array had resolution comparable to that of the deep array after accounting for the effects of linear refraction. That is, if the deep array could resolve two wave trains that differed only slightly in direction, the shallow array could also resolve the wave trains assuming that the beach had parallel depth contours and that linear refraction theory was valid.

Figure 1 also shows the nearly planar bathymetry of the site, with depth contours based on a survey conducted on September 9, 1980 (within one day of acquiring the data presented below). Least squares fit of the tide-corrected depth measurements to a plane resulted in an on-offshore direction $264^{\circ} \mathrm{T}$ (i.e., the beach normal is $\sim 6^{\circ}$ south of west) and a mean slope of 0.02 . The two arrays were very nearly aligned with the depth contours, with the axis of the deep array rotated $1^{\circ}$ clockwise (i.e., $355^{\circ} \mathrm{T}$ ) with respect to the depth contours, and the axis of the shallow array rotated $3^{\circ}$ clockwise $\left(357^{\circ} \mathrm{T}\right)$. In the following, all angles will be referred to an on-offshore coordinate system, with $0^{\circ}$ corresponding to waves approaching normal to the beach, and 
positive angles corresponding to waves approaching the beach from the north (angles greater than $264^{\circ} \mathrm{T}$ ).

Data acquisition and calculation of Fourier coefficients of sea surface elevation are described in detail in FG. Time series of measurements every $0.5 \mathrm{~s}$ were constructed for each instrument by block averaging raw data sampled at 64 Hz. The time series were partitioned into 1024-s records and Fourier transformed. Where necessary, Fourier coefficients of near-bottom pressure were converted to coefficients of local sea surface elevation using the linear, finite-depth theory. For each record, the complex cross-spectral matrix between all sensors in a given directional array was averaged over eight frequency bands, yielding frequency resolution of $0.0078 \mathrm{~Hz}$. The cross spectrum was then ensemble averaged over 20 records, resulting in estimates having 320 degrees of freedom.

At each frequency, high-resolution directional spectra were calculated from the averaged cross-spectral matrix and the known sensor positions using an iterative maximum likelihood (IMLE) technique [Pawka, 1983; Oltman-Shay and Guza, 1984]. Starting with an initial maximum likelihood estimate of the directional spectrum [e.g., Davis and Regier, 1977], the IMLE method converges upon a possible true spectrum (i.e., one that can be used to retrieve the measured cross spectrum) by "unsmoothing" successive maximum likelihood estimates. The IMLE technique has been shown to yield accurate, high-resolution directional spectra from arrays and wave conditions that are very similar to those discussed here [Pawka, 1982, 1983].

\section{MeAsured SPECTRA}

In this study we analyze in detail a single 5 -h period on September 10, 1980. The data were obtained on a falling tide, with a total depth change of $1 \mathrm{~m}$ over the $5 \mathrm{~h}$. The mean depth was $10.33 \mathrm{~m}$ at the deep array and $4.12 \mathrm{~m}$ at the shallow array. Measured sea surface elevation variances were $\sim 360 \mathrm{~cm}^{2}$ and $\sim 430 \mathrm{~cm}^{2}$ at the deep and shallow arrays, respectively. Although similar directional measurements were obtained on 11 other occasions during the monthlong deployment, we present this particular data set because it exhibits a diversity of directional shoaling and refraction effects.

\subsection{Frequency Spectra}

One-dimensional frequency spectra measured at the center of each array and averaged over the entire $5 \mathrm{~h}$ are shown in Figure 2. At both array locations, the frequency spectrum is dominated by a narrow peak centered at $0.06 \mathrm{~Hz}$. In $10 \mathrm{~m}$ depth, a broader peak extends from $\sim 0.09$ to $0.13 \mathrm{~Hz}$. Less than $16 \%$ of the total variance is contributed by motions at frequencies greater than $0.13 \mathrm{~Hz}$. Although the lowfrequency swell peak is still present at the shallow array $(4 \mathrm{~m}$ depth), the band $0.09-0.13 \mathrm{~Hz}$ now contains two significant peaks, centered at $0.10 \mathrm{~Hz}$ and at $0.12 \mathrm{~Hz}$. Futhermore, although the spectrum continues to decrease at higher frequencies, there is a broad, low peak in the frequency range $0.16-0.20 \mathrm{~Hz}$, centered near $0.18 \mathrm{~Hz}$.

\subsection{Frequency-Directional Spectra}

IMLE estimates of frequency-directional spectra at the two arrays are shown in Figure 3. At $10 \mathrm{~m}$ depth (Figure 3a), virtually all of the observed wave energy is found within

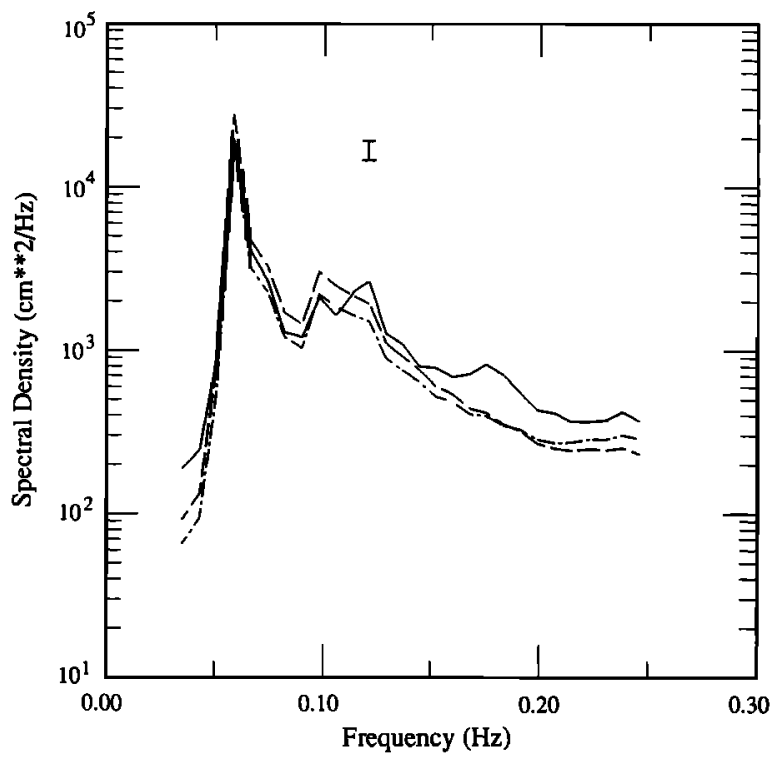

Fig. 2. Frequency spectra (320 degrees of freedom) of sea surface elevation for September 10, 1980. Shown are the measured spectrum at $10 \mathrm{~m}$ depth (dash-dot line), the prediction of LFDT at 4 $m$ depth obtained by integrating (1) using the measured frequencydirectional spectrum in $10 \mathrm{~m}$ depth (dashed line), and the measured spectrum at $4 \mathrm{~m}$ depth (solid line). Bar indicates $95 \%$ confidence interval for spectral estimates.

$\pm 25^{\circ}$ of normal incidence. The dominant low-frequency swell $(0.05-0.09 \mathrm{~Hz}$ in Figure 2) is approaching the beach from the south (i.e., negative angular directions), and is bimodal with major and minor peaks centered at $(f=\mathbf{0 . 0 6}$ $\left.\mathrm{Hz}, \theta=-4^{\circ}\right)$ and $\left(0.08 \mathrm{~Hz},-13^{\circ}\right)$, respectively. For frequencies above $\sim 0.09 \mathrm{~Hz}$, most of the energy is approaching from the northern quadrant. In the frequency band $0.09-0.13 \mathrm{~Hz}$, the waves are propagating primarily from the north $\left(\sim 2-17^{\circ}\right)$, with the broadest distribution at the low-frequency end of this range. The frequency-directional data (Figure 3a) show that the single broad peak in the one-dimensional frequency spectrum at $0.09-0.13 \mathrm{~Hz}$ (Figure 2) is composed of waves propagating from both the northern and the southern quadrants.

The frequency-directional spectrum at the shallow array (Figure $3 b$ ) shows that the waves evolved significantly through the shoaling region. The peaks at the shallow array are typically narrower, of higher amplitude, and closer to the beach normal than are their counterparts at the deep array. Five distinct concentrations of variance are evident in Figure $3 b$ : the low-frequency swell seen at the deep array, centered at $f=0.06 \mathrm{~Hz}$ and propagating from $-4^{\circ}$ (with a secondary maximum at $\left(\sim 0.08 \mathrm{~Hz},-8^{\circ}\right)$; a broad peak with maximum at $\left(0.10 \mathrm{~Hz},+10^{\circ}\right)$; additional wave trains propagating from $-4^{\circ}$ at $0.12 \mathrm{~Hz}$ and $0.18 \mathrm{~Hz}$; and a low peak centered at $(0.16$ $\left.\mathrm{Hz},+6^{\circ}\right)$. The three low-frequency maxima in the twodimensional spectrum $(f=0.06,0.10$, and $0.12 \mathrm{~Hz})$ correspond to the spectral peaks in the frequency spectrum (Figure 2) discussed above. The single, broad peak in the frequency spectrum $(f=0.16-0.20 \mathrm{~Hz})$ is evidently composed of two distinct wave trains, with the lower-frequency portion propagating from $+6^{\circ}$ and the higher-frequency portion from $-4^{\circ}$. 

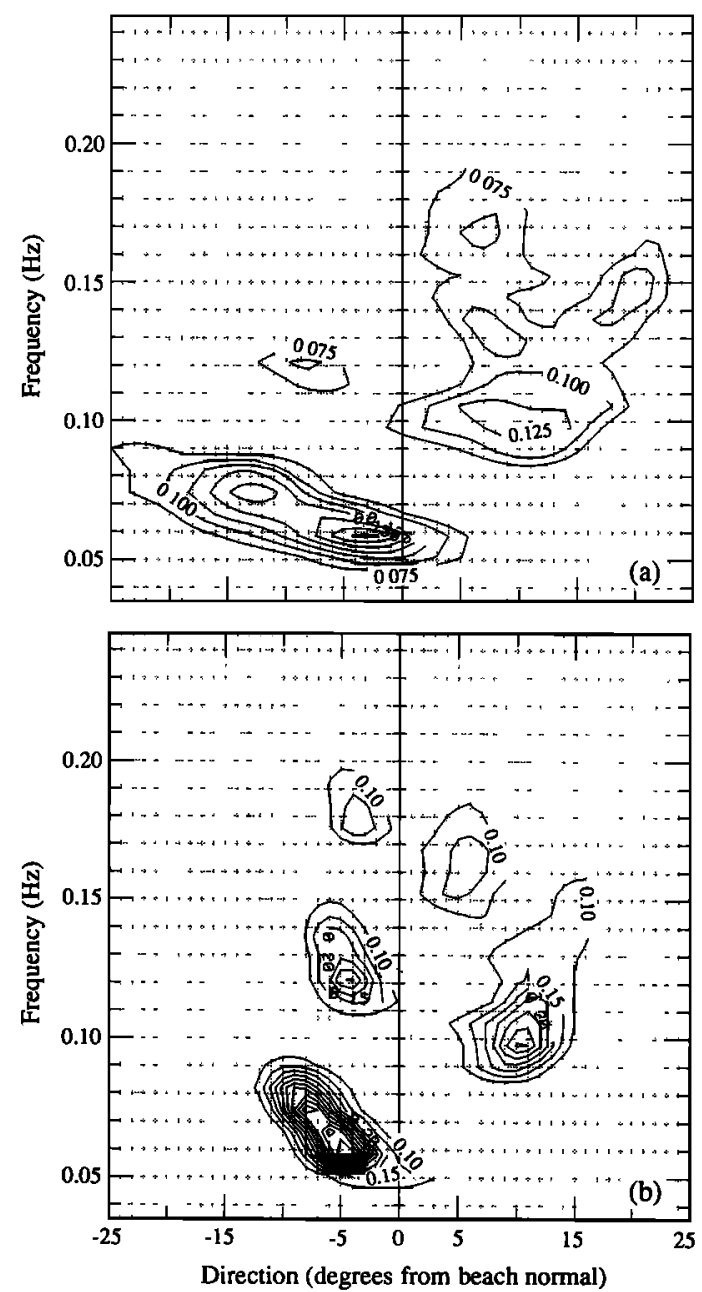

Fig. 3. Measured mean frequency-directional spectra: $(a) 10 \mathrm{~m}$ depth; (b) $4 \mathrm{~m}$ depth. At each frequency, the variance is distributed linearly with direction while the total area under each curve is proportional to the logarithm of the autospectral density at that frequency. The frequency resolution is $0.0078 \mathrm{~Hz}$.

\section{Comparisons With Predictions of Linear ShoAling Theory}

Linear, finite-depth theory (LFDT) can be used to estimate the transformation of the two-dimensional wave field between the deep and shallow arrays if the bottom slope is small, the waves neither gain energy (e.g., from the wind) nor lose energy through breaking and bottom friction, and if nonlinear effects are negligible. In the data considered here, the bottom slope is indeed small and input from the wind and losses resulting from bottom friction are expected to be negligible owing to the small $(246 \mathrm{~m})$ separation between the arrays. Wave breaking between the arrays was not visually apparent.

If the depth contours are everywhere straight and parallel, LFDT can be written as [LeMéhaute and Wang, 1982]

$$
S(f, \theta)=\frac{k C_{g 0}}{k_{0} C_{g}} S_{0}\left\{f, \sin ^{-1}\left[\frac{k}{k_{0}} \sin \theta\right]\right\}
$$

where $\theta$ is the angle between the beach normal and the wave number vector $\mathbf{k}, k \equiv|\mathbf{k}|, C_{g} \equiv(2 \pi) \partial f / \partial k$ is the group speed, the dispersion relation is given by $(2 \pi f)^{2}=g k \tanh k h$

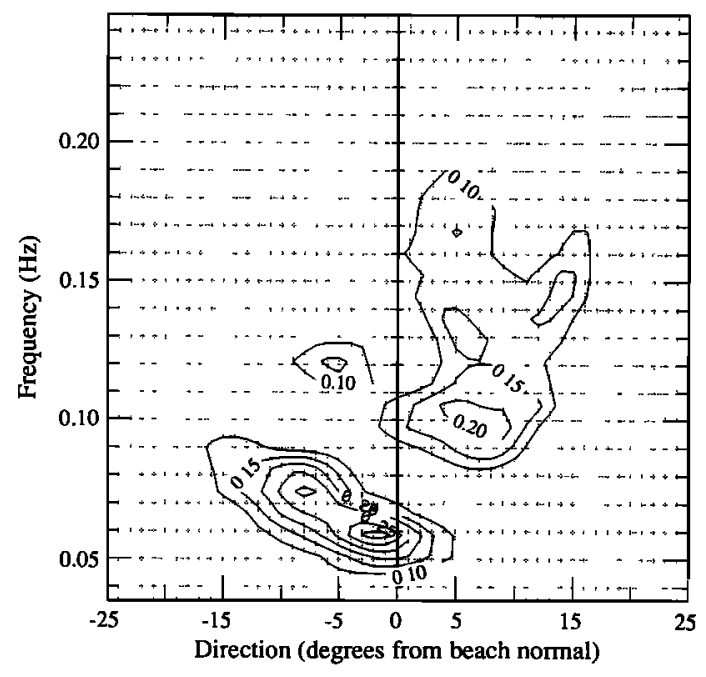

Fig. 4. Frequency-directional spectrum in $4 \mathrm{~m}$ depth predicted by LFDT using $10 \mathrm{~m}$ data as input. Contours are normalized as in Figure 3.

(where $h$ is the depth), and the subscript zero refers to initial conditions ( $10 \mathrm{~m}$ depth in the present study).

An estimate of $S(f, \theta)$ at the shallow array calculated using (1) and the measured frequency-directional spectra from the deep array is shown in Figure 4. Directional spectra (one-dimensional slices through $S(f, \theta)$ at fixed frequencies) measured at $10 \mathrm{~m}$ depth and both measured and predicted (by LFDT) at $4 \mathrm{~m}$ depth are shown in Figures $5 a-g$.

The following comparisons between measurements and LFDT predictions focus primarily on the angular location of local maxima in the directional spectra ("peaks"), and the total autospectral levels in given frequency bands. These quantities, as well as approximate sea surface elevation variances associated with individual directional peaks, are summarized in Table 1 for the directional spectra shown in Figure 5.

Directional spectra of the dominant low-frequency south swell $(0.06 \mathrm{~Hz})$ and the north sea $(0.10 \mathrm{~Hz})$ are shown in Figures $5 a$ and $5 b$, respectively. The directional spectra at both frequencies are essentially unimodal, and in each case LFDT overpredicts the total variance in the frequency band by approximately $30 \%$ and the refraction by about $2^{\circ}$. At $f=$ $0.07 \mathrm{~Hz}$ (between the swell and the sea frequencies, and corresponding to a local minimum in the frequency spectrum), the directional spectrum is also unimodal and LFDT again overpredicts total variance (by $20 \%$ ), but the direction of the peak is predicted to within $1^{\circ}$ (Figure $5 c$ ).

Figures $5 d-5 g$ show more complex directional distributions caused by sheltering of the Torrey Pines site by offshore islands and banks [Pawka, 1983; Pawka et al., 1984]. Comparisons of predicted and measured shallow directional spectra at these frequencies reveal more significant discrepancies in both peak directions and total band variances. At $f=0.12 \mathrm{~Hz}$ (Figure $5 d$ ), the directional spectrum in $10 \mathrm{~m}$ depth is bimodal with peaks of nearly equal magnitude centered at $-8^{\circ}$ and $+11^{\circ}$. Linear shoaling would cause the amplitudes to increase comparably and the peaks to refract by about $3^{\circ}$. The measurements, however, show that the amplitudes and modal directions are not well predicted by LFDT. The observed northern peak contains approximately the predicted variance, but its apparent direc- 
TABLE 1. Total Band Variances, Peak Directions, and Peak Variances for Directional Spectra in Figure 5

\begin{tabular}{|c|c|c|c|c|c|}
\hline \multicolumn{2}{|c|}{ 10-m Measured } & \multicolumn{2}{|c|}{ 4-m LFDT } & \multicolumn{2}{|c|}{ 4-m Measured } \\
\hline $\begin{array}{l}\text { Direction, } \\
\text { deg }\end{array}$ & $\begin{array}{c}\text { Variance, } \\
\mathrm{cm}^{2}\end{array}$ & $\begin{array}{l}\text { Direction, } \\
\text { deg }\end{array}$ & $\begin{array}{c}\text { Variance, } \\
\mathrm{cm}^{2}\end{array}$ & $\begin{array}{l}\text { Direction, } \\
\text { deg }\end{array}$ & $\underset{\substack{\text { Variance } \\
\mathrm{cm}^{2}}}{ }$ \\
\hline \multicolumn{6}{|c|}{$0.06 \mathrm{~Hz}$} \\
\hline-4 & $\begin{array}{l}18684^{*} \\
17188\end{array}$ & -2 & $\begin{array}{l}27969^{*} \\
27703\end{array}$ & -4 & $\begin{array}{l}19568^{*} \\
17346\end{array}$ \\
\hline \multicolumn{6}{|c|}{$0.07 \mathrm{~Hz}$} \\
\hline-13 & $\begin{array}{l}2283^{*} \\
1913\end{array}$ & -8 & $\begin{array}{l}3285^{*} \\
2810\end{array}$ & -8 & $\begin{array}{l}2667^{*} \\
2247\end{array}$ \\
\hline \multicolumn{6}{|c|}{$0.10 \mathrm{~Hz}$} \\
\hline+12 & $\begin{array}{l}2203^{*} \\
1783\end{array}$ & +8 & $\begin{array}{l}3030^{*} \\
2471\end{array}$ & +10 & $\begin{array}{l}2122^{*} \\
1743\end{array}$ \\
\hline \multicolumn{6}{|c|}{$0.12 \mathrm{~Hz}$} \\
\hline $\begin{array}{r}-8 \\
+11\end{array}$ & $\begin{array}{c}1501^{*} \\
651 \\
685\end{array}$ & $\begin{array}{l}-5 \\
+8\end{array}$ & $\begin{array}{c}1921^{*} \\
844 \\
907\end{array}$ & $\begin{array}{r}-4 \\
+12\end{array}$ & $\begin{array}{c}2621^{*} \\
1488 \\
998\end{array}$ \\
\hline \multicolumn{6}{|c|}{$0.14 \mathrm{~Hz}$} \\
\hline $\begin{array}{r}-5 \\
+7 \\
+17\end{array}$ & $\begin{array}{l}750^{*} \\
174 \\
235 \\
275\end{array}$ & $\begin{array}{r}-3 \\
+5 \\
+12\end{array}$ & $\begin{array}{l}912^{*} \\
217 \\
288 \\
374\end{array}$ & $\begin{array}{c}-6 \\
\cdots \\
+14\end{array}$ & $\begin{array}{c}1001^{*} \\
476 \\
\ddot{528}\end{array}$ \\
\hline \multicolumn{6}{|c|}{$0.16 \mathrm{~Hz}$} \\
\hline $\begin{array}{r}-6 \\
+7 \\
+21\end{array}$ & $\begin{array}{l}480^{*} \\
104 \\
216 \\
126\end{array}$ & $\begin{array}{r}-4 \\
+5 \\
+15\end{array}$ & $\begin{array}{l}540^{*} \\
124 \\
248 \\
162\end{array}$ & $\begin{array}{r}\ldots \\
+6 \\
+16\end{array}$ & $\begin{array}{l}689^{*} \\
\cdots \\
377 \\
167\end{array}$ \\
\hline \multicolumn{6}{|c|}{$0.18 \mathrm{~Hz}$} \\
\hline $\begin{array}{r}-8 \\
+8 \\
+15\end{array}$ & $\begin{array}{c}387^{*} \\
78 \\
168 \\
65\end{array}$ & $\begin{array}{r}-6 \\
+6 \\
+16\end{array}$ & $\begin{array}{c}415^{*} \\
87 \\
176 \\
80\end{array}$ & $\begin{array}{r}-4 \\
+6 \\
+16\end{array}$ & $\begin{array}{l}821^{*} \\
308 \\
266 \\
116\end{array}$ \\
\hline
\end{tabular}

* Total variance in frequency band.

tion $\left(+12^{\circ}\right)$ is comparable to the unrefracted direction observed at the deep array. The observed southern peak is located at $-4^{\circ}$ (rather than the predicted $-5^{\circ}$ ), but contains nearly twice the predicted variance. Overall, the measured autospectral density at this frequency exceeds the prediction of LFDT by a factor of 1.4, with nearly all of the discrepancy attributable to the large measured variance associated with the peak at $-4^{\circ}$.

Figure $5 e$ shows the directional spectrum at $f=0.14 \mathrm{~Hz}$, near the high-frequency edge of the isolated directional peak at $0.11-0.15 \mathrm{~Hz}$ in Figure $3 b$. The most striking discrepancy between measured and predicted 4-m spectra is the hugely amplified southern peak that is observed, but is not well predicted by LFDT. The LFDT prediction of this peak is in error by more than a factor of 2 in variance and $3^{\circ}$ in direction.

At $f=0.16 \mathrm{~Hz}$ (Figure $5 f$ ), both the $10-\mathrm{m}$ measured spectrum and the LFDT prediction are trimodal as at 0.14 $\mathrm{Hz}$, with predicted peaks in $4 \mathrm{~m}$ depth at $-4^{\circ},+5^{\circ}$, and $+15^{\circ}$. The shallow array data support the predictions for both the direction and the amplitude of the peak at $+15^{\circ}$, but the southerly peak (predicted to be located at $-4^{\circ}$ ) is not fully resolved. Most importantly, the measured directional spectrum is dominated by a peak centered at $+6^{\circ}$ and exceeding the LFDT prediction by a factor of 1.5 in variance.

The directional comparison at a relatively high frequency $(f=0.18 \mathrm{~Hz})$ is shown in Figure $5 g$. Based on LFDT, the directional spectrum at $4 \mathrm{~m}$ depth should be roughly trimodal, with minor peaks at $-6^{\circ}$ and $+16^{\circ}$, and a larger, broad peak with maximum at $+6^{\circ}$. The measurements confirm the minor peak at $+16^{\circ}$, but show considerably larger peaks at $+6^{\circ}$ (underpredicted by LFDT by a factor of 1.5 ) and at $-4^{\circ}$ (underpredicted by a factor of 3.5). The total autospectral density in this band is underpredicted by LFDT by nearly a factor of 2.

The field data analyzed above suggest that at frequencies less than $0.12 \mathrm{~Hz}$, LFDT predicts peak directions within a few degrees and total peak energies within about $30 \%$ (Figures $5 a-5 c$ ). At higher frequencies, errors in LFDT predictions of both directions and variances are significantly larger. In particular, the linear theory inaccurately predicts the large peaks observed in the southern quadrant at $0.12 \mathrm{~Hz}$ and $0.14 \mathrm{~Hz}$ (Figures $5 d$ and $5 e$ ), in the northern quadrant at $0.16 \mathrm{~Hz}$ (Figure $5 f$ ), and in both quadrants at $0.18 \mathrm{~Hz}$ (Figure $5 g$ ).

\section{Discrepancies Between LFDT and Data}

In the previous section, predictions of directional spectra based on linear shoaling theory were seen to differ substantially from observations in $\mathbf{4} \mathrm{m}$ depth. In the appendix, it is shown that the observed discrepancies are not primarily artifacts of the directional estimation technique. Other sources of error including depth variations during the run, 

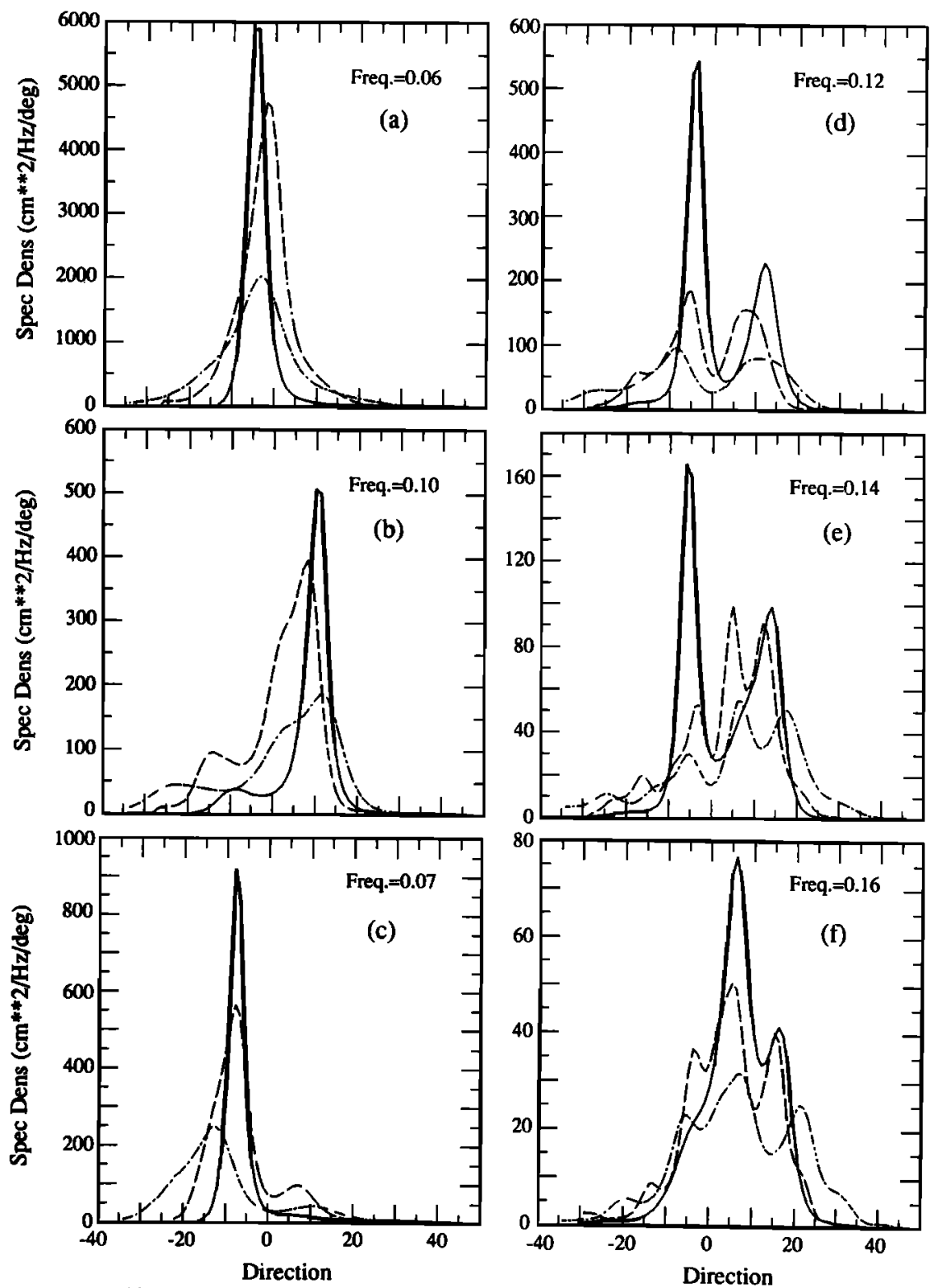

(degrees relative to beach normal)

(degrees relative to beach normal)

Fig. 5. Directional spectra at selected frequencies. Shown are measured spectra at $10 \mathrm{~m}$ depth (dash-dot lines), 4-m spectra predicted by LFDT based on 10-m measurements (dashed lines), and 4-m measurements (solid lines): (a) $f=$ $0.06 \mathrm{~Hz} ;(b) f=0.10 \mathrm{~Hz} ;(c) f=0.07 \mathrm{~Hz} ;(d) f=0.12 \mathrm{~Hz} ;(e) f=0.14 \mathrm{~Hz} ;(f) f=0.16 \mathrm{~Hz} ;(g) f=0.18 \mathrm{~Hz}$.

sensor placement errors, and data nonstationarity are believed to be relatively small. In this section, it is demonstrated that nonlinear wave-wave interactions can modify the amplitudes and directional distributions of shoaling wave fields to cause the discrepancies between LFDT and observations.

The shoaling models of FG and LYK suggest that wave transformation results from both linear conservation of energy flux and nonlinear, near-resonant triad interactions. The key requirement for near-resonant triad interactions is that both the frequencies and the vector wave numbers of the interacting waves must sum to (nearly) zero:

$$
\begin{gathered}
f_{1} \pm f_{2} \pm f_{3}=0 \\
\mathbf{k}_{1} \pm \mathbf{k}_{2} \pm \mathbf{k}_{3}=\mathbf{k}_{\delta} \quad\left|\mathbf{k}_{\delta}\right| /\left|\mathbf{k}_{1,2,3}\right| \ll 1
\end{gathered}
$$

In one-dimensional comparisons with field data [e.g., FG; Elgar et al., 1990], all waves were assumed to be propagating normal to a plane beach, so that $(2 b)$ reduced to a scalar equation relating the wave number magnitudes. Clearly, however, because $(2 b)$ is a vector equation, the nearresonant triad interactions can transfer energy across both frequencies (as in the one-dimensional model) and directions.

Elgar and Guza [1985b, 1986] and Doering and Bowen [1987] have used bispectral techniques to elucidate details of nonlinear triad interactions in the shoaling wave field. They showed that the bicoherence [Hasselmann et al., 1963] could be used as a measure of nonlinear coupling between modes even for shoaling waves, where each mode is simultaneously participating in multiple near-resonant triads. Large bicoher- 


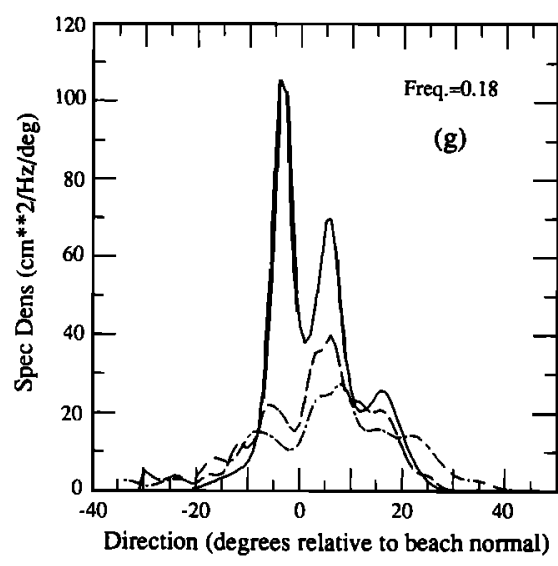

Fig. 5. (continued)

ence magnitudes indicated phase coupling between modes at different frequencies. Comparisons between data and the predictions of the FG model showed that for essentially narrow-banded wave fields such as the one considered in this study, small bicoherences indicated the absence of significant nonlinear interactions between the corresponding modes [Elgar and Guza, 1986].

Calculated bicoherences show, as expected, that nonlinearities in $4 \mathrm{~m}$ depth are stronger and more extensive than in $10 \mathrm{~m}$ depth in the present data set (compare Figures $6 a$ and $6 b$ ). For most triads with all three component frequencies above $0.05 \mathrm{~Hz}$ (the low-frequency cutoff used in the directional analyses), bicoherence values at the deep array are insignificant, suggesting little nonlinear coupling. The isolated significant bicoherences involve the autospectral peak; the frequencies of the interacting waves are $\left(f_{1}=\mathbf{0 . 0 6}, f_{2}=\right.$ $0.06),(0.06,0.08)$, and $(0.06,0.12)$, with the convention that the third frequency of each triad is given by $f_{3}=f_{1}+f_{2}$.

In $4 \mathrm{~m}$ depth (Figure $6 b$ ), waves at the autospectral peak $(\sim 0.06 \mathrm{~Hz})$ are significantly coupled to waves at all other frequencies, with particularly strong interactions at $(0.06$, $0.06),(0.06,0.07),(0.06,0.12)$, and $(0.06,0.16)$. Additional major nonlinear interactions are associated with the local bicoherence maxima at $(0.07,0.12),(0.09,0.12)$, and $(0.11$, 0.11 ).

As shown below, the major discrepancies between the observed and predicted frequency-directional spectra in $4 \mathrm{~m}$ depth occur at frequencies associated with bicoherence maxima (indicating significant nonlinear coupling), and the observed directions of anomalously energetic peaks are consistent with the vector resonance conditions (equation (2)).

\subsection{Interactions Between the Autospectral Peak and Its Harmonics}

The $4 \mathrm{~m}$ depth bicoherence maxima at $(0.06,0.06)$ and $(0.06,0.12)$ involve coupling of waves at the autospectral peak with themselves and their harmonics. The bicoherence peak at $(0.06,0.06)$ is the self-self-second harmonic degenerate triad. In this case, (2) becomes

$$
\begin{gathered}
2 f_{1}-f_{3}=0 \\
2 \mathbf{k}_{1}-\mathbf{k}_{3}=\mathbf{k}_{\delta} \quad\left|\mathbf{k}_{\delta}\right| \ll\left|\mathbf{k}_{1,3}\right|
\end{gathered}
$$

If the bicoherence maximum is due to a near-resonant triad, (3b) must be satisfied. Physically, the wave number of the second harmonic must be oriented in nearly the same direction as $\mathbf{k}_{1}$, and it must be nearly $2 k_{1}$ in magnitude. From the linear, finite depth dispersion relation, $k_{3} / 2 k_{1}=1.07$ in 10 $\mathrm{m}$ depth, and the ratio decreases to 1.02 in $4 \mathrm{~m}$ as the waves become less dispersive. Figures $3 b, 5 a$, and $5 d$ show that the major directional peak at $f=0.12 \mathrm{~Hz}$ is indeed collinear with the peak at the primary frequency $(f=0.06 \mathrm{~Hz})$. Furthermore, the observed concentration of variance at this direction is substantially underpredicted by linear shoaling theory (Figure $5 d$ and Table 1).

Similar results hold for the bicoherence maximum at $(0.06$, 0.12 ). In this case, $f_{1}=0.06 \mathrm{~Hz}$ in $(2 a), f_{2}=2 f_{1}=0.12 \mathrm{~Hz}$, $f_{3}=0.18 \mathrm{~Hz}$, and the resulting triad consists of modes with frequencies corresponding to the primary and its first two harmonics. The dispersion relation yields $k_{1}=0.0585 \mathrm{rad}$ $\mathrm{m}^{-1}, k_{2}=0.1236 \mathrm{rad} \mathrm{m}^{-1}$, and $k_{3}=0.1956 \mathrm{rad} \mathrm{m}^{-1}$ in $4 \mathrm{~m}$ depth, so $k_{3} /\left(k_{1}+k_{2}\right)=1.07$. Considering first the directions of the largest peaks in the measured directional spectra, the resonance condition $(2 b)$ suggests that the primary $(f=0.06$ $\mathrm{Hz}, \theta=-4^{\circ}$ ) interacting with the (nonlinearly generated) second harmonic peak $\left(0.12 \mathrm{~Hz},-4^{\circ}\right)$ should yield a directional peak at the third harmonic frequency $(0.18 \mathrm{~Hz})$ also at $-4^{\circ}$. The interaction of the primary with the smaller amplitude peak in Figure $5 d\left(0.12 \mathrm{~Hz},+12^{\circ}\right)$ should result in a secondary directional peak at $\left(0.18 \mathrm{~Hz},+7^{\circ}\right)$ if near-resonant triad interactions are significant. Peaks are, indeed, observed in the $0.18-\mathrm{Hz}$ directional spectrum at $-4^{\circ}$ and $+7^{\circ}$, and the large peak amplitudes are not predicted by LFDT (Figure 5g).

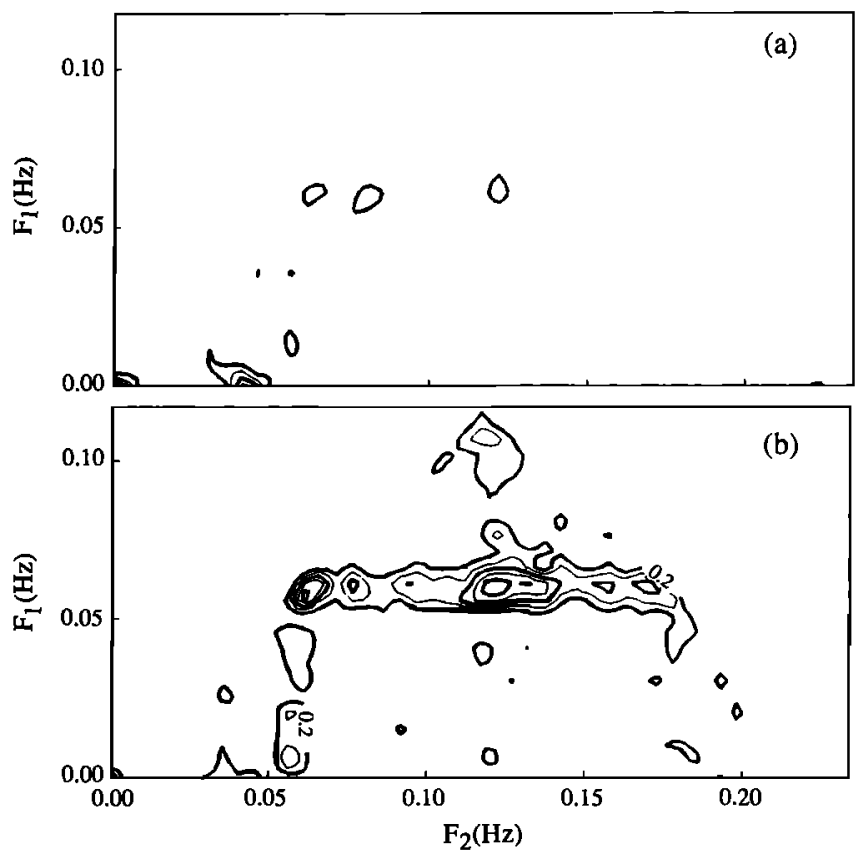

Fig. 6. Measured bicoherence spectra at (a) $10 \mathrm{~m}$ and (b) $4 \mathrm{~m}$ depths. Spectra have been averaged over 8 × 8 elementary frequency bands and 20 records. Nonsignificant bicoherence levels are not shown. Contour interval is 0.1 , with even contours (above the 90\% significance level) denoted by bold lines. 


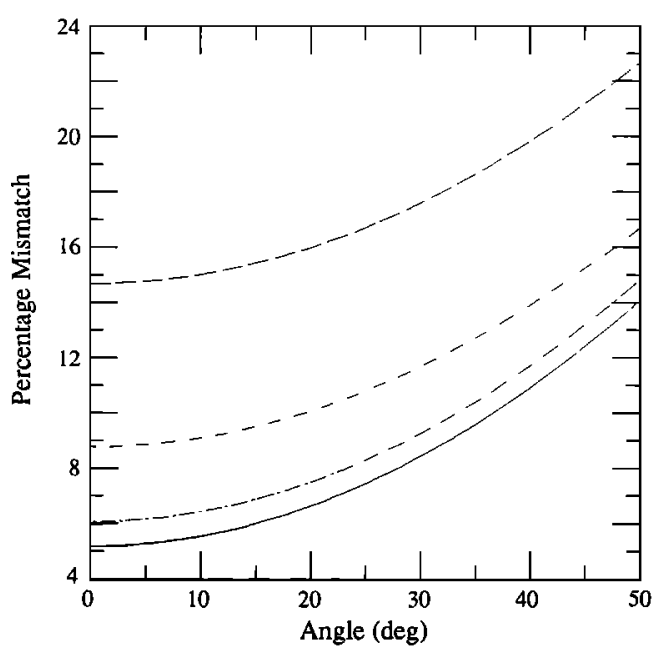

Fig. 7. Mismatch parameter (as defined in the text) at $7 \mathrm{~m}$ depth as a function of angle between the two lowest frequency waves in a triad. Solid line represents $(0.06 \mathrm{~Hz}, 0.06 \mathrm{~Hz}, 0.12 \mathrm{~Hz})$; long-dashed line, $(0.10 \mathrm{~Hz}, 0.10 \mathrm{~Hz}, 0.20 \mathrm{~Hz})$; dash-dot line, $(0.06 \mathrm{~Hz}, 0.07 \mathrm{~Hz}$, $0.13 \mathrm{~Hz})$; and short-dashed line, $(0.06 \mathrm{~Hz}, 0.10 \mathrm{~Hz}, 0.16 \mathrm{~Hz})$.

\subsection{Interactions Between the Primary and Nonharmonic Frequencies}

The interactions between the autospectral peak and its harmonics discussed in section 5.1 primarily involve waves propagating in the same direction. For any given triad of frequencies obeying $(2 a)$, such "collinear" interactions guarantee minimum mismatch in the wave number resonance condition, since any mismatch results only from lowest-order dispersion. Interactions between waves propagating in different directions must result in larger wave number mismatches (and hence less net near-resonant energy transfers) because the magnitude of the vector sum wave number $\left(k_{3}\right)$ must be smaller than required for a linear wave at the appropriate frequency. However, as noted in section 4, virtually all of the energy in the wind wave frequency band approached the beach within $25^{\circ}$ of normal incidence, and the most energetic waves at $0.06 \mathrm{~Hz}$ were nearly normally incident (angles of about $-4^{\circ}$ ). Wave number mismatch magnitudes (expressed as $1-\left|\mathbf{k}_{1}+\mathbf{k}_{2}\right| / k_{3}^{\text {lin }}$, where $k_{3}^{\text {lin }}$ is the magnitude of the linear wave number at frequency $f_{3}$ ) are shown in Figure 7 for several different triads at $7 \mathrm{~m}$ depth. For all interactions discussed below, the mismatches are small and relatively insensitive to wave direction, so approach direction has only a small effect on the magnitudes of near-resonant transfers. In the present data set, the principal effect of the directionality in the incident wave field is on the directions (rather than the magnitudes) of the nonlinearly generated waves.

The third largest maximum in the bicoherence spectrum is located near $(0.06,0.08)$. It represents interactions between two wave trains propagating from the south, although in $4 \mathrm{~m}$ depth the higher-frequency waves are $\sim 4^{\circ}$ farther from normal incidence than are the primary waves. The nonlinearly generated waves should be observed at the sum frequency (about $0.14 \mathrm{~Hz}$ ) and the vector sum direction $\left(-6.2^{\circ}\right)$. In fact, an anomalously large peak is observed at the proper direction in Figure $5 e$, and LFDT underpredicts its magnitude by nearly a factor of 2 . Additional interactions between the primary and the more southerly swell at fre- quencies around $0.08 \mathrm{~Hz}$ result in the elongated shape of the southern quadrant contours in the range $0.11-0.15 \mathrm{~Hz}$ in Figure $3 b$.

Of greater interest is the interaction at $(0.06,0.10)$ in Figure $6 b$, resulting in nonlinear energy transfers to waves with frequency $0.16 \mathrm{~Hz}$. Figures $5 a$ and $5 b$ show that each of the two lower-frequency waves in the triad are nearly unimodal in direction, with the $0.06-\mathrm{Hz}$ primary waves propagating from the south $\left(-4^{\circ}\right)$ and the $0.10-\mathrm{Hz}$ waves approaching from the north $\left(+10^{\circ}\right)$. The vector direction predicted by $(2 b)$ is $+4.8^{\circ}$, within one degree of the dominant peak observed in shallow water (Figure $5 f$ and Table 1 ).

\subsection{Interactions Away From the Autospectral Peak}

Unfortunately, most of the identified bicoherence maxima not involving the energetic swell at $0.06 \mathrm{~Hz}$ result in nonlinear transfers to high-frequency waves $(f>0.20 \mathrm{~Hz})$ which are directionally aliased by the deep array. Detailed comparisons between predictions of LFDT and measured spectra at $4 \mathrm{~m}$ depth are thus not possible. However, examination of Figure $3 b$ at $f=0.19 \mathrm{~Hz}$ shows that a local directional maximum exists at $\theta=+6^{\circ}$, corresponding to the bicoherence maximum at $(0.07,0.12)$. The direction of the observed minor peak in the directional spectrum is consistent with a near-resonant triad interaction similar to those discussed above.

Although not apparent in Figure $3 b$, similar small peaks are observed at $\left(0.22 \mathrm{~Hz},+3^{\circ}\right)$ and $\left(0.24 \mathrm{~Hz},-3^{\circ}\right)$. The first of these is consistent with interactions between the $0.10-\mathrm{Hz}$ waves propagating from the north and the second harmonic $(0.12 \mathrm{~Hz})$ from the south, while the second peak is yet a higher harmonic of the primary, forced jointly by the self-self interaction of the second harmonic $(0.12 \mathrm{~Hz}, 0.12 \mathrm{~Hz})$ and the primary-third harmonic interaction $(0.06 \mathrm{~Hz}, 0.18 \mathrm{~Hz})$.

\subsection{Discrepancies at $f=0.06 \mathrm{~Hz}$ and $f=0.10 \mathrm{~Hz}$}

As noted in section 4 (see Figures $5 a$ and $5 b$ ), the observed directions of the south swell $(0.06 \mathrm{~Hz})$ and the north sea $(0.10$ $\mathrm{Hz}$ ) did not agree with predictions of LFDT. In each case, the observed location of the directional peak in $4 \mathrm{~m}$ depth was $2^{\circ}$ farther from normal incidence than predicted, and the low-frequency swell even appeared to have refracted away from normal incidence as the depth decreased.

The discrepancies are not readily attributed to uncertainties in array alignment or knowledge of the beach normal, since modal directions at frequencies away from the autospectral peaks and their harmonics are predicted well by LFDT (e.g., Figure 5c).

From the analysis above (and especially Figure $6 b$ ), it is clear that both the south swell and the higher-frequency north sea are participating in nonlinear, near-resonant triad interactions. As shown explicitly in FG and LYK, such interactions can result in modal phase modifications that can be interpreted as nonlinear changes to the wave number. Since the wave number magnitudes used in the calculations of directional spectra are determined by LFDT, the effective wave number magnitudes may differ from the predicted ones, thus contributing to discrepancies between the observed directional spectra and the predictions of LFDT. Additionally, the true local direction may indeed by altered by nonlinear effects. 


\subsection{The 10-m Directional Spectra}

Nonlinearities in $10 \mathrm{~m}$ depth result in statistically significant bicoherences, although the bicoherence magnitudes are much smaller than those found in shallow water (compare Figures $6 a$ and $6 b$ ). The bicoherence maxima in Figure $6 a$ at $(0.06,0.06)$ and $(0.06,0.12)$ are the manifestations in $10 \mathrm{~m}$ depth of the harmonic interactions discussed in detail (for shallow water) in section 5.1. However, in $10 \mathrm{~m}$ depth the observed harmonic peak $\left(0.12 \mathrm{~Hz},-8^{\circ}\right)$ is not precisely aligned with the fundamental $\left(\theta=-4^{\circ}\right)$. The local maximum in the $10-\mathrm{m}$ directional spectrum at $0.18 \mathrm{~Hz}\left(\theta=-8^{\circ}\right.$; Figure $5 g$ ) is also displaced from the primary. In $10 \mathrm{~m}$ depth, a significant fraction of the total energy at harmonic frequencies is from presumably free waves propagating from the north (cf. Figures $5 d$ and $5 g$ ). Additionally, there is a $19 \%$ difference between the LFDT wave number used in the IMLE directional estimates and the wave number of waves at $0.18 \mathrm{~Hz}$ that are bound to, and forced by, the primary at $0.06 \mathrm{~Hz}$. The relatively low energy levels in the southern quadrant and large wave number differences between bound and free waves could cause errors in the estimated directions of the harmonic peaks, thus resulting in the apparent misalignment.

Hasselmann et al. [1963] compared similar bispectral results in $11 \mathrm{~m}$ depth to the predictions of a nonresonant, second-order Stokes-type theory valid for small Ursell number. They noted agreement between observed and predicted bispectra. However, typical Pacific swell in $11 \mathrm{~m}$ depth has Ursell number $\sim 0.3$, and the wave number mismatch parameter (section 5.2) between the primary and its second harmonic is small $(\sim 0.08)$. Swell waves in $10-12 \mathrm{~m}$ depth are thus in the transition region between nonresonant bound wave and near-resonant triad interactions, and neither theory is expected to be highly accurate. Had the Hasselmann et al. observations been obtained in $7 \mathrm{~m}$ depth (rather than 11 $\mathrm{m})$, the agreement with nonresonant theory may not have been as good. The connection between shallow water, near-resonant Boussinesq theory, and nonresonant bound wave theory has not been fully explored, but is important in any model describing the propagation of nonlinear waves from deep to shallow water.

\section{Discussion and Conclusions}

Surface wave frequency-directional spectra $(S(f, \theta))$ measured in $4.1 \mathrm{~m}$ depth on a natural beach have been compared with the predictions of linear, finite-depth theory (LFDT; see equation (1)). Estimates of $S(f, \theta)$ measured in $10.3 \mathrm{~m}$ depth, $246 \mathrm{~m}$ seaward of the shallow array, were used to initialize the LFDT refraction model. The inadequacies of LFDT for the prediction of essentially one-dimensional quantities (i.e., Fourier coefficients of sea surface elevation at a point) are evident even in the autospectral comparisons (Figure 2), and have been well documented [e.g., Freilich and Guza, 1984; Elgar and Guza, 1985a, 1986]. The present study shows additionally that LFDT based on observations in $10 \mathrm{~m}$ depth cannot be used to predict accurately the directional distributions of shoaled waves in $4 \mathrm{~m}$ depth.

Freilich and Guza [1984] and Liu et al. [1985] have developed models describing the shoaling transformation as a combination of linear and nonlinear effects, the latter resulting from near-resonant triad interactions between weakly dispersive waves. These models predict the nonlinear excitation of waves with frequencies and wave numbers satisfying triad near-resonance conditions (equations (2a) and $(2 b)$ ). Consistent with the resonance conditions, a series of observed directional peaks at harmonic frequencies (e.g., $f=0.12,0.18,0.24 \mathrm{~Hz}$ ) are aligned with the dominant south swell $\left(f=0.06 \mathrm{~Hz}, \theta=-4^{\circ}\right)$ in $4 \mathrm{~m}$ depth (Figures $3 b, 5 d$, and 5g). Previous observations [Freilich and Guza, 1984; Elgar and Guza, 1985a] showing only directional alignment between the primary and its second harmonic were limited by array size and estimator resolution. In the present study, using better arrays and more sophisticated directional estimates, the alignment has been observed for the third and fourth harmonics, as well. For the first time, clear evidence has been presented for coupling between independent wave trains (e.g. $0.06 \mathrm{~Hz}$ and $0.10 \mathrm{~Hz}$, and $0.06 \mathrm{~Hz}$ and $0.08 \mathrm{~Hz}$ ) approaching the beach from different directions, with energy transferred to a third mode at the sum frequency and the vector sum direction as predicted by the resonance conditions.

Based on our analysis, an heuristic nonlinear "model" predicting the locations of directional peaks can be constructed when the autospectrum is dominated by a narrow, low-frequency swell, and the wind waves at frequencies less than twice the swell frequency have nearly unimodal directional distributions. Under these conditions, the dominant nonlinear triad sum interactions involve the waves at the autospectral peak. By assigning $k_{1}$ in $(2 b)$ to the vector wave number associated with the swell and similarly $\mathbf{k}_{2}$ to the wave number of waves at each higher frequency, the resonance conditions (equation ( $2 b)$ ) yield the predicted peak vector wave number (and hence, direction) at the sum frequency. The "model" is thus valid for waves with frequencies exceeding twice the swell frequency.

Comparisons between these heuristic "predicted" directions and the observed peak directions at higher frequencies in $4 \mathrm{~m}$ depth are shown in Figure 8 . With the exception of a single frequency just below the third harmonic of the swell, "predicted" and observed peak directions differ by at most $1^{\circ}$. The agreement is made even more remarkable by the fact that the observed peak directions vary by nearly $12^{\circ}$ (and from southern to northern quadrants) across the frequency band $0.12-0.21 \mathrm{~Hz}$ (see Figure $3 b$ ).

The peak directions in $4 \mathrm{~m}$ depth predicted by LFDT are also shown in Figure 8. Although LFDT is reasonably accurate at frequencies less than the second harmonic of the swell, it is typically in error by more than $9^{\circ}$ at higher frequencies. Curiously, at $f=0.12,0.16$, and $0.17 \mathrm{~Hz}$, LFDT appears to predict the observed peak direction to within $1^{\circ}$. The apparently accurate predictions of the linear model can be explained by the measured $10-\mathrm{m}$ bicoherences in $10 \mathrm{~m}$ depth (Figure 6a). As discussed in section 5.5, significant bicoherence maxima are observed near $(0.06,0.06)$ and $(0.06,0.12)$, and nonlinearly generated waves nearly aligned with the swell are present even in the observed $10-\mathrm{m}$ directional spectra. Thus, although the LFDT model based on the 10-m observations "correctly" predicts peak directions at discrete frequencies in shallow water, the directional spectra at those frequencies (see, for example, Figures $4,5 d$, and $5 f$ ) show that LFDT underpredicts the amplitudes of the peaks in $4 \mathrm{~m}$ depth by nearly a factor of 2 . The significant underprediction of peak amplitudes at those frequencies indicates that LFDT does not contain the essential physics 


\section{MODEL - OBSERVED PEAK DIRECTIONS}

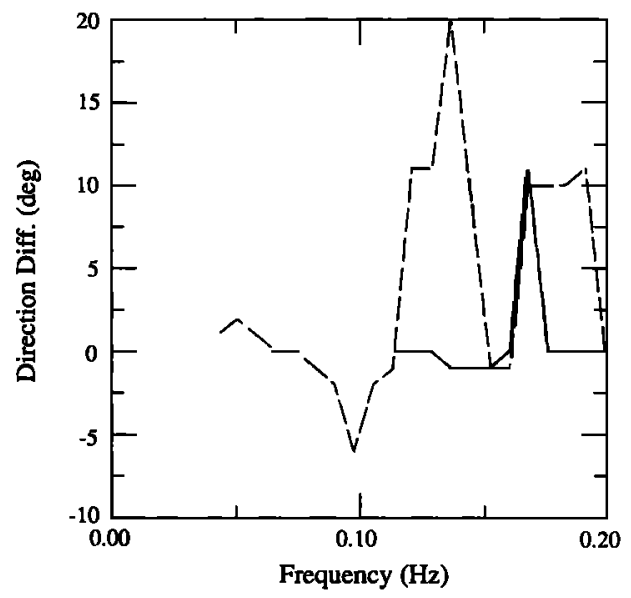

Fig. 8. Angular differences between predicted and observed peak directions $\left(\theta_{\text {pred }}-\theta_{\text {obs }}\right)$ in $4 \mathrm{~m}$ depth. Solid line represents heuristic nonlinear "model" of section 6; dashed line, LFDT.

needed to predict wave shoaling, while Boussinesq models based on triad nonlinear interactions do.

In the data studied here, the peak directions in $4 \mathrm{~m}$ depth at frequencies between 0.12 and $0.21 \mathrm{~Hz}$ were determined primarily by nonlinear effects. Although full prediction of the two-dimensional spectrum (both directions and amplitudes at each frequency) requires application of a nonlinear twodimensional shoaling model such as that of Liu et al. [1985], the present results clearly show that the effects of nearresonant triad interactions are detectable in field observations of frequency-directional spectra of shoaling waves.

\section{APPENDIX: Estimation ERrors}

Estimation of directional spectra from sparse longshore arrays as used in this study is not straightforward, and much effort in the past two decades has been expended to develop and test improved spectral estimation techniques. The IMLE technique used here (cf. section 2) was originally developed and tested using arrays and wave conditions at Torrey Pines that were very similar to those in this study [Pawka, 1982, 1983]. The technique is highly accurate for this particular situation and its performance is relatively insensitive to changes in initial conditions, array configurations, and choices of convergence parameters. Nonetheless, there is no mathematical formulation justifying IMLE, confidence levels on $S(f, \theta)$ are unknown, and the resulting estimated directional spectra are probably not even unique solutions. Although the present objective is to investigate shoaling waves (not to evaluate estimators), tests have been performed to eliminate the possibility that the "observed" directional spectra are primarily artifacts of the estimation process.

Two simulations were performed in which known directional spectra were used to generate noise-free crossspectral matrices for a given array configuration. Directional spectra were then estimated from the simulated cross spectra and compared with the known inputs. In the first case, the inputs were taken to be the spectra at $4 \mathrm{~m}$ depth predicted by using deep array measurements and LFDT

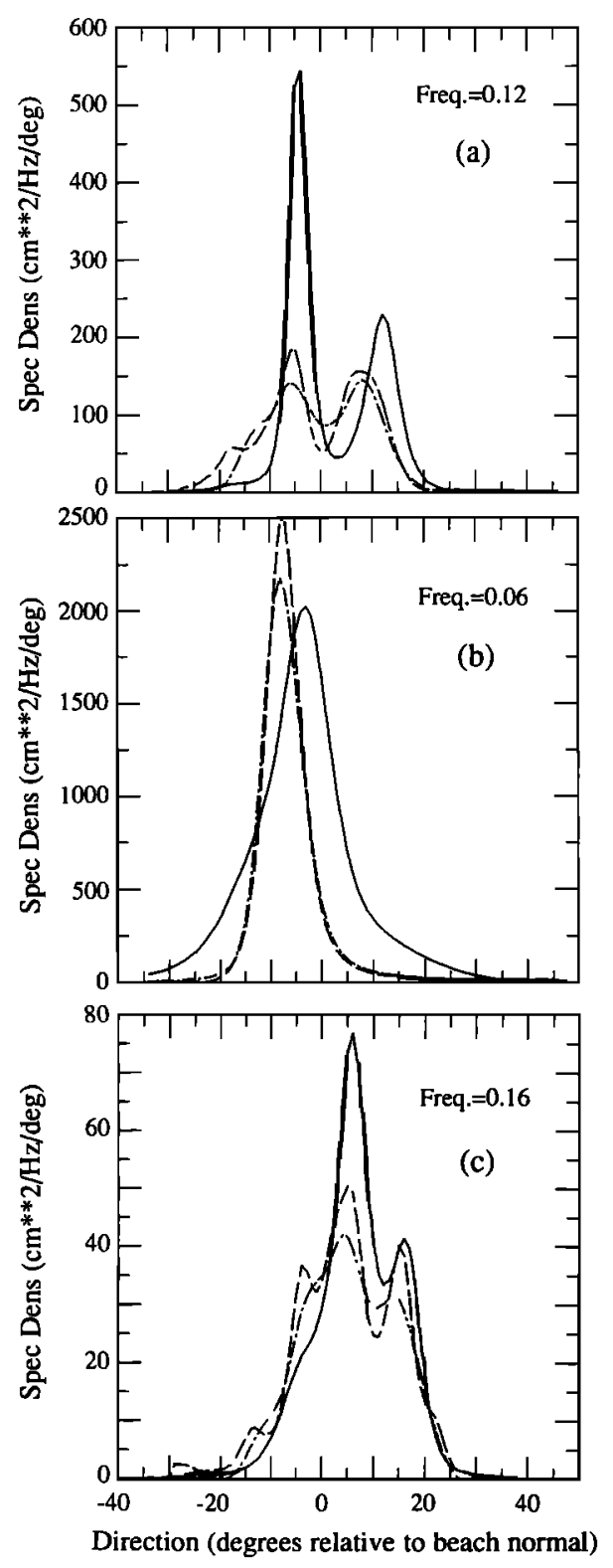

Fig. 9. Results of model tests of the arrays at selected frequencies. Shown on each panel are input spectra (dashed lines), output spectra (dash-dot lines), and measured spectra (solid lines). (a) Shallow array test at $f=0.12 \mathrm{~Hz}$ using as input the linear prediction in $4 \mathrm{~m}$ depth. (b) Deep array test at $f=0.06 \mathrm{~Hz}$ using as input the linear prediction at $10 \mathrm{~m}$, based on the measured spectrum at $4 \mathrm{~m}$ depth. (c) Shallow array test at $f=0.16 \mathrm{~Hz}$.

(i.e., the input spectra were the dashed lines in Figures $5 a-5 g$ ). Cross spectra appropriate to the shallow array instrument locations were then generated, and the retrieved IMLE spectral estimates ("output spectra") were compared with the "input spectra." In similar fashion, measured shallow array spectra were used as input to (1), the resulting LFDT predictions at $10 \mathrm{~m}$ depth were used to generate the cross spectra at the deep array instrument locations, and output IMLE directional spectra were calculated. Examples at selected frequencies are shown in Figures $9 a-9 c$. In each case, the discrepancies between input and output test spectra are small compared with the differences between the input (or output) and the measured spectra. 


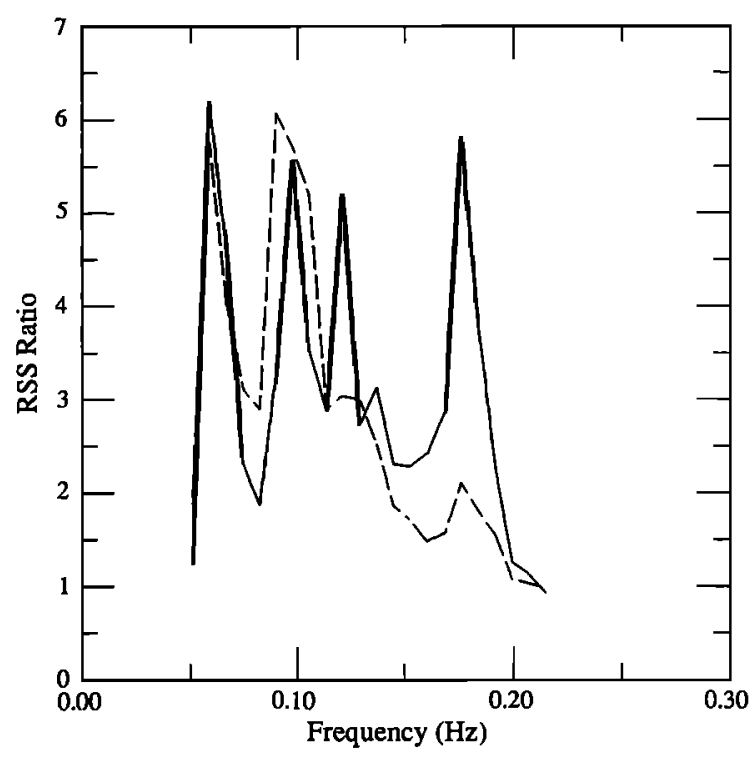

Fig. 10. Plots of $R(f)$ (equation (A1)) versus frequency for the test of the shallow array (solid line) and the deep array (dashed line).

Quantitative comparisons were obtained by calculating root-sum-square (rss) differences between input, output and measured directional spectra at each frequency. Denoting the input (derived from LFDT), measured (at $4 \mathrm{~m}$ or $10 \mathrm{~m}$ depth), and output (as described above) directional spectra by $S_{i}(f, \theta), S_{m}(f, \theta)$, and $S_{o}(f, \theta)$ respectively, the rss difference ratio is given by

$$
\begin{aligned}
& R(f) \\
& =\left(\sum_{\theta}\left[S_{m}(f, \theta)-S_{i}(f, \theta)\right]^{2} / \sum_{\theta}\left[S_{o}(f, \theta)-S_{i}(f, \theta)\right]^{2}\right)^{1 / 2}
\end{aligned}
$$

Large values of $R(f)$ result when the rss difference between a measured directional spectrum and the LFDT prediction is large compared with the "error" of the IMLE estimator.

Figure 10 shows $R(f)$ for both simulations. At all frequencies between $0.05 \mathrm{~Hz}$ and $0.21 \mathrm{~Hz}, R(f)>1$, indicating that deviations between the output spectra and the input (LFDT) spectra are small when compared with the deviations between measured and LFDT predicted spectra. Local maxima in $R(f)$ at $0.06,0.10,0.12$, and $0.18 \mathrm{~Hz}$ correspond to the inaccurate predictions of LFDT shown in Figures $5 a, 5 b, 5 d$, and $5 g$. At $0.06 \mathrm{~Hz}$ and $0.10 \mathrm{~Hz}$, the large errors result from small angular differences in the locations of the narrow unimodal peaks as discussed in section 5.4 . At $0.12 \mathrm{~Hz}$ and $0.18 \mathrm{~Hz}$, the shapes of input and output spectra differ qualitatively from the measured spectra owing to the nonlinear effects discussed in sections 4 and 5 . At $0.16 \mathrm{~Hz}$ (Figure $5 f$ ), $R=2.4$ for the shallow test; although significant differences between the measured directional spectrum and the simulated output are evident in Figure $9 c$ (i.e., the large observed peak at $+6^{\circ}$ ), the magnitude of the rss ratio is not as large as at other frequencies. The above tests are neither as comprehensive nor as sophisticated as those of Pawka cited above; however, the results imply that observed discrepancies between LFDT predictions and measured/ estimated directional spectra result from the deficiencies in the LFDT model, and are not artifacts of the spectral estimation technique.

Acknowledgments. Portions of this analysis were conducted at the Jet Propulsion Laboratory, California Institute of Technology, under contract with NASA. Additional support for this work was provided by the Physical Oceanography program of the National Science Foundation (NSF). The data were acquired by the Center for Coastal Studies, Scripps Institution of Oceanography, during a field experiment supported by the Office of Naval Research (ONR). R. L. Lowe was principal engineer for the field experiment. T. H. C. Herbers made several helpful suggestions that improved the analysis.

\section{REFERENCES}

Collins, J. I., Prediction of shallow water spectra, J. Geophys. Res., 77, 2693-2707, 1972.

Davis, R. E., and L. A. Regier, Methods for estimating directional wave spectra from multi-element arrays, J. Mar. Res., 35, 453-477, 1977.

Doering, J., and A. Bowen, Skewness in the nearshore zone: A comparison of estimates from Marsh-McBirney current meters and colocated pressure sensors, J. Geophys. Res., 92, $13,173-13,183,1987$.

Elgar, S., and R. T. Guza, Shoaling surface gravity waves: Comparisons between field observations, linear theory, and a nonlinear model, J. Fluid Mech., 158, 47-70, 1985a.

Elgar, S., and R. T. Guza, Observations of bispectra of shoaling surface gravity waves, J. Fluid Mech., $161,425-448,1985 b$.

Elgar, S., and R. T. Guza, Nonlinear model predictions of bispectra of shoaling surface gravity waves, J. Fluid Mech., 167, 1-18, 1986.

Elgar, S., M. H. Freilich, and R. T. Guza, Model-data comparisons of moments of nonbreaking shoaling surface gravity waves, $J$. Geophys. Res., in press, 1990.

Freilich, M. H., and R. T. Guza, Nonlinear effects in shoaling surface gravity waves, Philos. Trans. R. Soc. London, Ser. A, $311,1-41,1984$.

Hasselmann, K., W. Munk, and G. MacDonald, Bispectra of ocean waves, in Time Series Analysis, edited by M. Rosenblatt, pp. 125-139, John Wiley, New York, 1963.

Hom-ma, M., K. Horikawa, and Y. Chao, Sheltering effects of Sado Island on wind waves off Niigata Coast, Coastal Eng. Jpn., 9, $27-44,1966$.

LeMéhaute, B., and J. D. Wang, Wave spectrum changes on sloped beach, J. Waterw. Port Coastal Ocean Div. Am. Soc. Civ. Eng., 108, 33-47, 1982.

Liu, P.L.-F., S. B. Yoon, and J. T. Kirby, Nonlinear refractiondiffraction of waves in shallow water, J. Fluid Mech., 153, 185-201, 1985.

Longuet-Higgins, M. S., On the transformation of a continuous spectrum by refraction, Proc. Cambridge Philos. Soc., 53(1), 226-229, 1957.

Oltman-Shay, J., and R. T. Guza, A data-adaptive ocean wave directional spectrum estimator for pitch and roll type measurements, J. Phys. Oceanogr., 14, 1800-1810, 1984.

Pawka, S. S., Wave directional characteristics on a partially sheltered coast, Ph.D. dissertation, 246 pp., Univ. of Calif. at San Diego, La Jolla, 1982.

Pawka, S. S., Island shadows in wave directional spectra, J. Geophys. Res., 88, 2579-2591, 1983.

Pawka, S. S., D. L. Inman, and R. T. Guza, Island sheltering of surface gravity waves: Model and experiment, Cont. Shelf Res., 3, 35-53, 1984.

Peregrine, D. H., Equations for water waves and the approximations, behind them, in Waves on Beaches and Resulting Sediment Transport, edited by R. E. Meyer, pp. 95-122, Academic, San Diego, Calif., 1972.

Peregrine, D. H., and R. Smith, Nonlinear effects upon waves near caustics, Philos. Trans. R. Soc. London, 292, 341-370, 1979. 
Peregrine D. H., and G. P. Thomas, Finite-amplitude deep water waves on currents, Philos. Trans. R. Soc. London, 292, 371-390, 1979.

Wilson, W. S., D. G. Wilson, and J. A. Michael, Analysis of swell near the island of Aruba, J. Geophys. Res., 78, 7834-7844, 1973.

S. L. Elgar, Electrical and Computer Engineering, Washington State University, Pullman, WA 99164.
M. H. Freilich, Jet Propulsion Laboratory, California Institute of Technology, Pasadena, CA 91109.

R. T. Guza, Center for Coastal Studies, Scripps Institution of Oceanography, La Jolla, CA 92093.

(Received June 12, 1989;

accepted August 8, 1989.) 